\title{
IMPLEMENTASI KEBIJAKAN TENTANG PEDOMAN HIDUP ISLAMI WARGA MUHAMMADIYAH
}

\section{POLICY IMPLEMENTATION ON MUHAMMADIYAH CITIZENS' ISLAMIC LIVING GUIDELINES}

\author{
Abdul Hadi Amri Yusuf ${ }^{*}$, Erry Sunarya ${ }^{2}$, Ike Rachmawati ${ }^{3}$ \\ 1,2,3 Program Studi Magister Ilmu Administrasi, Fakultas Ilmu Administrasi dan Humaniora, \\ Universitas Muhammadiyah Sukabumi, Jl. R. Syamsudin, SH No. 50, Cikole, Kota Sukabumi, \\ Jawa Barat 43113
}

*Korespondensi: Abdul Hadi Amri Yusuf. Email: ahad@ummi.ac.id

(Diterima: 10-03-2021; Ditelaah: 02-04-2021; Disetujui: 05-05-2021)

\begin{abstract}
The Muhammadiyah Citizens' Islamic Living Guidelines (PHIWM) have not been thoroughly implemented especially for the educational personnels of Sukabumi Muhammadiyah University. One of indications is, there are still education personnel who do not heed the values contained in PHIWM, especially related to managing business charities such as in the last two years there are still delays in entering work and complaints about the performance of education personnel. This research aims to qualitatively describe the policy implementation on PHIWM for the educational personnels of Sukabumi Muhammadiyah University. Results of this research indicate that the objectives of PHIWM implementation to shape the individual and collective behaviors of all Muhammadiyah members who show a good example have not been fully implemented, especially for the educational personnels of Sukabumi Muhammadiyah University. Nevertheless, there are some activities that can show a good standard of behavioral example as an effort to realize PHIWM objectives. Those activities are building the common prayer times, regular study and performance assessment aimed at improving the work performance and in accordance with PHIWM values for the educational personnels of Sukabumi Muhammadiyah University.
\end{abstract}

Key words: Educational Personnel, PHIWM, Policy Implementation, UMMI.

\begin{abstract}
ABSTRAK
Pedoman Hidup Islami Warga Muhammadiyah (PHIWM) belum terimplementasi secara menyeluruh terutama di kalangan tenaga kependidikan Universitas Muhammadiyah Sukabumi. Hal ini ditunjukkan dengan masih adanya tenaga kependidikan yang tidak mengindahkan nilai-nilai yang terkandung dalam PHIWM terutama kaitannya dengan mengelola amal usaha seperti dalam dua tahun terakhir masih adanya keterlambatan masuk kerja dan komplain terhadap kinerja tenaga kependidikan. Penelitian ini bertujuan untuk mendeskripsikan secara kualitatif implementasi kebijakan tentang PHIWM pada tenaga kependidikan Universitas Muhammadiyah Sukabumi. Hasil penelitian menunjukkan bahwa tujuan implementasi PHIWM untuk membentuk perilaku individu dan kolektif seluruh anggota Muhammadiyah yang menunjukkan keteladanan yang baik belum sepenuhnya terlaksana terutama bagi tenaga kependidikan Universitas Muhammadiyah Sukabumi. Namun demikian, terdapat beberapa aktivitas yang dapat menunjukkan ukuran perilaku keteladanan yang baik sebagai usaha untuk merealisasikan tujuan PHIWM. Beberapa aktivitas tersebut adalah menjalankan waktu shalat berjamaah, pengajian rutin dan penilaian kinerja yang bertujuan untuk meningkatkan performa kerja dan sesuai dengan nilai-nilai PHIWM bagi tenaga kependidikan Universitas Muhammadiyah Sukabumi.
\end{abstract}

Kata kunci: Implementasi Kebijakan, PHIWM, Tenaga Kependidikan, UMMI.

Yusuf, Abdul Hadi Amri; Sunarya, Erry \& Rachmawati, Ike. (2021). Implementasi Kebijakan Tentang Pedoman Hidup Islami Warga Muhammadiyah. Jurnal GOVERNANSI, 7(2): 111-120. 


\section{PENDAHULUAN}

Universitas Muhammadiyah Sukabumi merupakan salah satu lembaga pendidikan di bawah naungan persyarikatan Muhammadiyah yang didirikan berdasarkan kajian dan studi kelayakan yang dilakukan pengurus Pimpinan Daerah Muhammadiyah (PDM) Sukabumi tanggal 1 Desember 2000 yang memutuskan untuk segera merealisasikan Keputusan Musyawarah Daerah Muhammadiyah 1996, yaitu mendirikan Universitas Muhammadiyah Sukabumi (UMMI) dengan kampus yang berada di Komplek Perguruan Muhammadiyah Jl. R. Syamsudin, SH No. 50 Sukabumi. Tujuan didirikannya UMMI adalah sebagai berikut: (1) Membangun masyarakat dalam segala aspek kehidupannya, (2) Membangun masyarakat Islami yang sebenar-benarnya, (3) Membangun nilai-nilai kearifan lokal dalam bidang teknologi, pertanian, budaya, pendidikan dan budaya ekonomi lokal yang pada akhirnya mencapai tingkat global.

Tujuan pembangunan UMMI berkaitan erat dengan falsafah Pendidikan Tinggi Muhammadiyah, yaitu mengembangkan keilmuan dan Al-Islam, berilmu dan beramal demi membangun bangsa dan negara. Selain itu, UMMI sebagai Perguruan Tinggi Muhammadiyah dituntut untuk mengimplementasikan Pedoman Hidup Islami Warga Muhammadiyah (PHIWM) sebagai pedoman warga Muhammadiyah untuk menjunjung tinggi agama Islam sehingga terwujudnya masyarakat Islam yang sebenar-benarnya terutama di lingkungan Kampus Universitas Muhammadiyah Sukabumi.

Di lingkungan Universitas Muhammadiyah Sukabumi terdapat unit kerja yang bekerja di bidang kepegawaian, yaitu kepala bagian kepegawaian dengan tugas pokok dan fungsi (tupoksi) salah satunya adalah mengelola administrasi pegawai, termasuk di dalamnya, yaitu kehadiran, kedisiplinan dan juga tanggung jawab. Selain itu, di Universitas Muhammadiyah Sukabumi juga terdapat unit kerja yang rutin mengadakan pengajian di setiap minggunya, yaitu
Lembaga Al-Islam dan Kemuhammadiyahan, dari unit ini dapat mengetahui salah satu indikator yang tertuang dalam PHIWM di atas.

Berdasarkan data yang diperoleh dari Bagian Kepegawaian, dalam dua tahun terakhir, Bagian Kepegawaian telah mengeluarkan surat pemberitahuan keterlambatan masuk kerja sebanyak 45 surat pemberitahuan pertama dan surat pemberitahuan kedua sebanyak 16 untuk tenaga kependidikan, dan juga komplain yang masuk untuk tenaga kependidikan UMMI sebanyak 24 komplain sejak tahun 2017, sebagaimana ditunjukkan pada Tabel 1.

Tabel 1. Daftar Surat Peringatan dan Komplain Tenaga Kependidikan UMMI

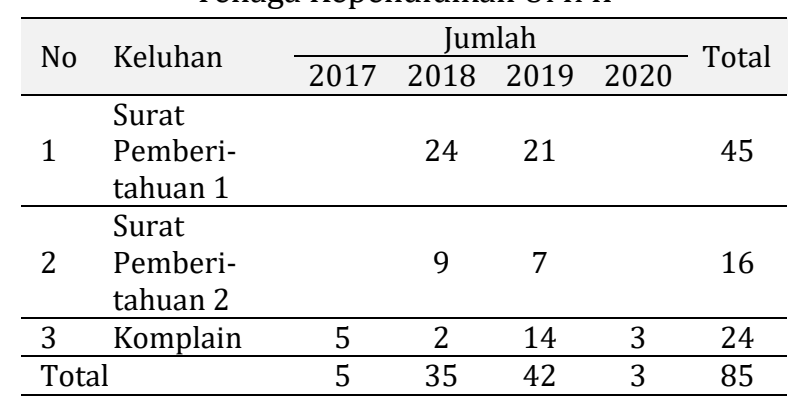

Sumber: Bagian Kepegawaian UMMI (2020)

Dengan demikian dapat diketahui bahwa PHIWM di UMMI belum terimplementasi secara menyeluruh, dan peneliti tertarik untuk mengetahui sejauhmana tenaga kependidikan di UMMI mengimplementasikannya. Pengenalan dan sosialisasi tentang PHIWM telah dilaksanakan dan terus ditingkatkan agar pemahaman dan implementasi pedoman tersebut dapat lebih terealisasi di lingkungan Universitas Muhammadiyah Sukabumi. Hal demikian penting karena referensi yang digunakan dalam pedoman tersebut bersumber dari Al-Quran dan Sunnah.

Berdasarkan gambaran latar belakang yang diuraikan di atas, maka peneliti tertarik untuk membahas implementasi kebijakan tentang PHIWM pada tenaga kependidikan Universitas Muhammadiyah Sukabumi. 


\section{MATERI DAN METODE}

\section{Konsep/Teori yang Relevan}

Dalam kaitan dengan penelitian ini terdapat dua konsep yang relevan, yaitu implementasi kebijakan dan Pedoman Hidup Islami Warga Muhammadiyah.

\section{Implementasi Kebijakan}

Kebijakan publik menurut Jenkins (dalam Michael Hill, 1993: 34) adalah suatu keputusan berdasarkan hubungan kegiatan yang dilakukan oleh aktor politik guna menentukan tujuan dan mendapat hasil berdasarkan pertimbangan situasi tertentu. Kebijakan publik dibedakan dengan bentukbentuk kebijakan yang lain misalnya kebijakan swasta. Hal ini dipengaruhi oleh keterlibatan faktor-faktor bukan pemerintah. Kemudian menurut Easton (dalam Taufiqurokhman, 2014: 3), kebijakan publik didefinisikan sebagai alokasi nilai-nilai secara sah kepada seluruh anggota masyarakat (the authoritative allocation of values for the whole society).

Suatu kebijakan yang telah dirumuskan tentunya memiliki tujuan tertentu yang ingin dicapai. Tujuan tersebut akan tercapai apabila kebijakan telah terimplementasi dengan baik. Oleh karena itu, untuk dapat diketahui apakah tujuan tersebut dapat tercapai atau tidak, maka kebijakan harus diimplementasikan. Jika kebijakan tidak diimplementasikan, maka kebijakan yang dirumuskan akan sia-sia dan tujuan yang telah ditentukan sebelumnya tidak akan pernah tercapai.

Implementasi kebijakan menurut Tachjan (2008: 24) dapat dimaksudkan sebagai suatu aktivitas yang berkaitan dengan pelaksanaan suatu pekerjaan dengan menggunakan alat untuk mencapai tujuan. Sedangkan implementasi kebijakan menurut Van Meter dan Van Horn (1975: 447) adalah tindakan-tindakan yang dilakukan baik oleh individu-individu atau pejabat-pejabat atau kelompok-kelompok pemerintah atau swasta yang diarahkan pada tercapainya tujuan-tujuan yang telah digariskan dalam keputusan kebijakan (actions by public and private individuals (or groups) that are directed at the achievement of objectives set forth in prior policy decisions).

Implementasi kebijakan menurut Van Meter dan Van Horn (1975) disebut sebagai a model of the policy implementation process. Keduanya mengemukakan enam variabel yang membentuk keterkaitan (linkage) antara kebijakan dan pencapaian/ kinerja (performance), sebagaimana ditunjukkan pada Gambar 1.

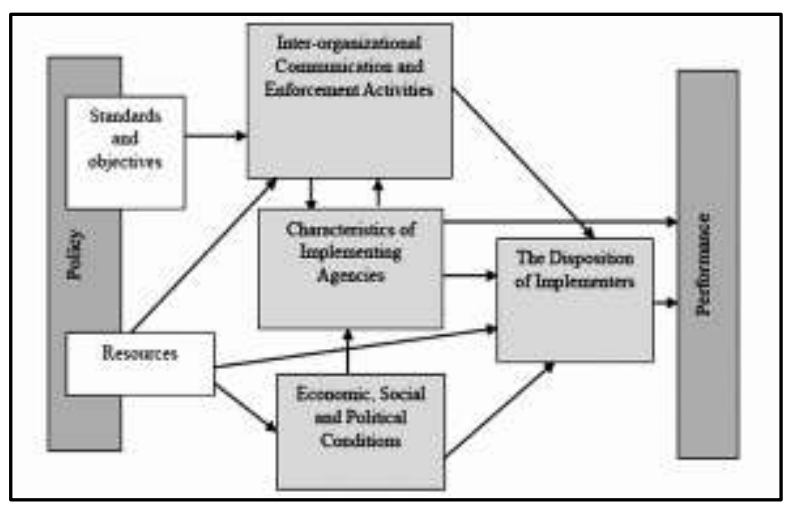

Sumber: Van Meter \& Van Horn (1975: 463)

\section{Gambar 1. Model Implementasi Kebijakan} menurut Van Meter dan Van Horn

Keenam variabel implementasi kebijakan menurut Van Meter dan Van Horn (1975) dapat diuraikan sebagai berikut:

1. Ukuran dan Tujuan Kebijakan: Ukuran dan tujuan kebijakan merupakan salah satu komponen yang penting dalam analisis implementasi kebijakan, penentuan penilaian ini menilai sejauh mana ukuran-ukuran dasar dan tujuantujuan kebijakan telah direalisasikan.

2. Sumber Daya Kebijakan: Keberhasilan proses implementasi kebijakan sangat tergantung dari kemampuan memanfaatkan sumber daya yang tersedia. Manusia merupakan sumber daya yang terpenting dalam menentukan suatu keberhasilan proses implementasi. Pada tahap-tahap tertentu dari keseluruhan proses implementasi kebijakan menuntut adanya sumber daya manusia yang berkualitas. 
3. Karakteristik Badan Pelaksana: Karakteristik badan-badan administratif akan mempengaruhi pencapaian kebijakan, dimana karakteristik ini tidak terlepas dari struktur birokrasi. Komponen ini meliputi ciri-ciri struktur formal dan informal organisasi serta atributatribut yang personal.

4. Sikap/Kecenderungan Pelaksana: Terdapat tiga unsur pendapat pelaksana yang dapat mempengaruhi kemampuan dan keinginan mereka untuk melaksanakan kebijakan, yaitu: (1) kognisi (pemahaman) tentang kebijakan, (2) arah kecenderungan-kecenderungan pelaksana terhadap ukuran-ukuran dan tujuan (penerimaan, netral, penolakan), dan (3) intensitas tanggapan.

5. Komunikasi antar Organisasi dan Aktivitas Pelaksana: Implementasi kebijakan yang efektif ditentukan oleh kejelasan ukuran-ukuran dan tujuantujuan yang dinyatakan oleh ketepatan dan konsistensi dalam mengkomunikasikan dan mengkoordinasikan ukuran dan tujuan tersebut untuk direalisasikan. Komunikasi dan koordinasi merupakan mekanisme yang ampuh dalam implementasi kebijakan publik. Semakin baik komunikasi dan kordinasi diantara pihak-pihak yang terlibat dalam suatu proses implementasi, kesalahan kecil akan terhindar jika berkoordinasi dan berkomunikasi dengan baik.

6. Kondisi Lingkungan Ekonomi, Sosial dan Politik: Lingkungan ekonomi, sosial dan politik adalah sejumlah lingkungan eksternal organisasi yang turut mendorong keberhasilan kebijakan yang telah ditetapkan sebelumnya. Kondisi lingkungan ekonomi, sosial dan politik yang tidak dapat menjadi sumber kegagalan dalam proses implementasi kebijakan. Karena itu, penting dalam proses implementasi kebijakan memperhatikan kondisi lingkungan eksternal organisasi.

\section{Pedoman Hidup Islami Warga Muham- madiyah}

Pedoman Hidup Islami Warga Muhammadiyah (PHIWM) adalah seperangkat nilai dan norma Islami yang bersumber pada Al-Qur'an dan Sunnah untuk menjadi pola bagi tingkah laku warga Muhammadiyah dalam menjalani kehidupan seharihari sehingga tercermin kepribadian Islami menuju terwujudnya masyarakat Islam yang sebenar-benarnya.

Pedoman Hidup Islami Warga Muhammadiyah merupakan pedoman untuk menjalani kehidupan dalam lingkup pribadi, keluarga, bermasyarakat, berorganisasi, mengelola amal usaha, berbisnis, mengembangkan profesi, berbangsa dan bernegara, melestarikan lingkungan, mengembangkan ilmu pengetahuan dan teknologi, dan mengembangkan seni dan budaya yang menunjukkan perilaku uswah hasanah (teladan yang baik).

\section{Metode}

Dalam suatu penelitian, seorang peneliti harus menggunakan metode penelitian yang tepat, hal ini dimaksud agar peneliti dapat memperoleh gambaran yang jelas mengenai masalah yang dihadapi serta langkah-langkah yang digunakan dalam mengatasi masalah tersebut. Adapun metode penelitian yang digunakan dalam penelitian ini adalah metode penelitian kualitatif. Alasan menggunakan metode penelitian ini agar dapat diketahui suatu keadaan organisasi secara alamiah, terdeskripsi melalui pengamatan seharihari dimana peneliti terlibat langsung di dalamnya.

Menurut Sugiyono (2013), penelitian kualitatif adalah suatu metode penelitian yang berlandaskan pada filsafat post positivisme, digunakan untuk meneliti pada kondisi objek yang alamiah dimana peneliti adalah sebagai instrumen kunci, pengambilan sampel sumber data dilakukan secara purposif, teknik pengumpulan dengan triangulasi, analisis data bersifat induktif/ 
kualitatif, dan hasil penelitian kualitatif lebih menekankan makna daripada generalisasi. Penelitian kualitatif bertumpu pada latar belakang alamiah secara holistik, memposisikan manusia sebagai alat penelitian, mementingkan proses daripada hasil serta hasil penelitian disepakati oleh peneliti dan subjek penelitian.

Adapun teknik sampling yang di digunakan dalam penelitian ini ialah menggunakan teknik purposive sampling. Purposive sampling merupakan salah satu teknik sampling non random sampling dimana peneliti menentukan pengambilan sampel dengan cara menetapkan ciri-ciri khusus yang sesuai dengan tujuan penelitian sehingga dapat menjawab permasalahan dan pertanyaan pokok penelitian. Menurut Sugiyono (2013: 218219) purposive sampling adalah teknik pengambilan sampel atau sumber data dengan pertimbangan tertentu.

\section{HASIL DAN PEMBAHASAN}

Implementasi berhubungan dengan tindakan atau pelaksanaan terhadap rencana yang sudah disusun secara matang dan terperinci. Untuk mengukur implementasi kebijakan pedoman PHIWM pada tenaga kependidikan Universitas Muhammadiyah Sukabumi, peneliti menggunakan enam dimensi, yaitu: (1) ukuran dan tujuan kebijakan, (2) sumber daya kebijakan, (3) karakteristik badan pelaksana, (4) sikap/ kecenderungan pelaksana, (5) komunikasi antar organisasi dan aktivitas pelaksana, serta (6) kondisi lingkungan ekonomi, sosial dan politik. Adapun pembahasan keenam dimensi tersebut dalam kaitannya dengan implementasi kebijakan PHIWM pada tenaga kependidikan Universitas Muhammadiyah Sukabumi adalah sebagai berikut:

\section{Ukuran dan Tujuan Kebijakan}

Kinerja implementasi kebijakan dapat dilihat dari tingkat keberhasilan ukuran dan tujuan kebijakan. Tujuan implementasi kebijakan tentang Pedoman Hidup Islami
Warga Muhammadiyah (PHIWM) tercantum dalam bagian pertama yang berbunyi "terbentuknya perilaku individu dan kolektif seluruh anggota Muhammadiyah yang menunjukkan keteladanan yang baik (uswatun hasanah) menuju terwujudnya masyarakat Islam yang sebenar-benarnya".

Tenaga kependidikan Universitas Muhammadiyah Sukabumi pada umumnya mengetahui tentang tujuan PHIWM. Pengetahuan tentang tujuan PHWIM tersebut didapat dari hasil membaca dan sosialisasi. Namun demikian, suatu kebijakan harus memenuhi unsur tujuan dan realisasinya. Dalam proses implementasinya, untuk mencapai tujuan tersebut terdapat beberapa aktivitas yang dapat menunjukkan keteladanan yang baik (uswatun hasanah) menuju terwujudnya masyarakat Islam yang sebenar-benarnya di kalangan tenaga kependidikan Universitas Muhammadiyah Sukabumi sebagai usaha dalam merealisasikan tujuan dari PHIWM. Adapun aktivitas-aktivitas tersebut seperti tadarus rutinan, mengindahkan waktu shalat, menunaikan shalat berjamaah, kultum rutinan dalam setiap pertemuan dan berinfaq, serta aktivitas bekerja yang selama ini menjadi ciri khas dari etos kerja dan disiplin Muhammadiyah yang mengandung nilai ibadah.

Aktivitas-aktivitas tersebut merupakan ukuran-ukuran yang dapat menunjukkan realisasi tujuan PHIWM terutama bagi tenaga kependidikan dalam aspek kehidupan pribadi, organisasi, masyarakat dan mengelola amal usaha. Dengan demikian, apabila aktivitas-aktivitas tersebut dilakukan secara istiqomah atau bersifat kontinyu, kemudian dilakukan secara bekerja sama yang melibatkan pimpinan dan karyawan (tenaga kependidikan) serta benar-benar menjadi tekad dan kesungguhan hati, maka peneliti berkeyakinan bahwa tujuan dari PHIWM akan terwujud sehingga Universitas Muhammadiyah Sukabumi tampil sebagai perguruan tinggi Islam yang istiqomah dan memiliki ghirah yang tinggi dalam mengamalkan ajaran Islam. 


\section{Sumber Daya Kebijakan}

Implementasi kebijakan tentu saja membutuhkan sumber daya yang dapat mendorong dan memperlancar implementasi kebijakan tersebut. Sumber daya yang tersedia yang dapat mendorong dan memperlancar implementasi kebijakan tentang PHIWM bagi tenaga kependidikan Universitas Muhammadiyah Sukabumi adalah sumber daya manusia. Sumber daya manusia yang dimaksud adalah sumber daya manusia yang memiliki kualitas, kapasitas dan pemahaman serta mampu menterjemahkan isi dari PHIWM. Sumber daya manusia yang memiliki kemampuan tersebut dapat mengajak seluruh warga kampus terutama tenaga kependidikan untuk kemudian dapat memberikan pengaruh dan seruan atau ajakan melalui kegiatan-kegiatan yang dapat memberikan pemahaman tentang isi dan maksud PHIWM.

Selain sumber daya manusia, terdapat sumber daya lain, yaitu sumber daya sarana dan prasarana, serta sumber daya finansial. Sumber daya sarana dan prasarana merupakan sumber daya yang tersedia seperti adanya fasilitas masjid yang digunakan dalam aktivitas-aktivitas pengajian rutinan. Kemudian tersedianya buku pedoman PHWIM yang dapat dibaca dan dipahami oleh warga kampus terutama tenaga kependidikan Universitas Muhammadiyah Sukabumi. Adapun sumber daya finansial, yaitu tersedianya anggaran yang dapat dimanfaakan untuk keperluan aktivitasaktivitas yang menunjang usaha tercapainya tujuan PHIWM salah satunya, yaitu untuk pemeliharaan sarana dan prasarana serta untuk distribusi buku-buku PHIWM untuk kemudian dapat dimiliki oleh seluruh warga kampus terutama tenaga kependidikan Universitas Muhammadiyah Sukabumi.

\section{Karakteristik Badan Pelaksana}

Karakteristik badan-badan administratif akan mempengaruhi pencapaian kebijakan, dimana karakteristik ini tidak terlepas dari struktur birokrasi. Komponen ini meliputi ciri-ciri struktur formal dan informal organisasi serta atribut-atribut yang personal. Beberapa unsur yang berpengaruh terhadap suatu organisasi dalam mengimplementasikan kebijakan adalah salah satunya tingkat pengawasan hirarki terhadap keputusan-keputusan subunit dan proses-proses dalam badan pelaksana. Dalam proses implementasi PHIWM pada tenaga kependidikan Universitas Muhammadiyah Sukabumi, terdapat adanya dukungan dari pimpinan khususnya kepada tenaga kependidikan dalam mengimplementasikan PHIWM di lingkungan Universitas Muhammadiyah Sukabumi. Hal ini juga menjadi sebuah kewajiban bagi pimpinan amal usaha Muhammadiyah untuk bisa menciptakan suasana kehidupan Islami dalam amal usaha yang menjadi tanggung jawabnya (Kehidupan Dalam Mengelola Amal Usaha).

\section{Sikap/Kecenderungan Pelaksana}

Sikap/kecenderungan pelaksana akan banyak mempengaruhi keberhasilan atau tidaknya kinerja implementasi kebijakan publik. Terdapat tiga unsur pendapat pelaksana yang dapat mempengaruhi kemampuan dan keinginannya untuk melaksanakan kebijakan, yaitu: (1) kognisi (pemahaman tentang kebijakan) (2) arah kecenderungan pelaksana terhadap ukuran dan tujuan kebijakan, dan (3) intensitas tanggapan. Terdapat beberapa tanggapan atau jawaban yang memberikan alasan mengapa PHIWM sangat penting untuk diimplementasikan terutama bagi tenaga kependidikan Universitas Muhammadiyah Sukabumi, yaitu:

a. Sebagai usaha dalam mewujudkan tujuan Persyarikatan Muhammadiyah, yaitu menjunjung tinggi agama Islam sehingga terwujudnya masyarakat Islam yang sebenar-benarnya.

b. Sebagai penuntun dalam mewujudkan kehidupan yang Islami di lingkungan 
amal usaha Muhammadiyah terutama Universitas Muhammadiyah Sukabumi.

c. Sebagai kewajiban warga Muhammadiyah dalam melaksanakan dan mengamalkan ajaran Islam dengan mempraktekkan kehidupan Islami dalam segala aspek kehidupan.

d. Sebagai pedoman tenaga kependidikan dalam memelihara dan mengembangkan amal usaha Universitas Muhammadiyah Sukabumi yang menjadi bentuk pengabdian kepada Allah Subhanahu wa taala dan berbuat kebijakan terhadap sesama.

\section{Komunikasi antar Organisasi dan Aktivitas Pelaksana}

Implementasi kebijakan akan berjalan efektif bila ukuran dan tujuan dipahami oleh individu yang bertanggung jawab dalam kinerja kebijakan. Oleh karena itu, sangat penting untuk memberi perhatian yang besar kaitannya dengan kejelasan ukuran dasar dan tujuan kebijakan melalui komunikasi dan koordinasi kepada para pelaksana dan dilakukan secara konsisten sebagai usaha dalam mewujudkan tujuan diimplementasikannya suatu kebijakan.

Dalam mencapai keberhasilan implementasi kebijakan tentang Pedoman Hidup Islami Warga Muhammadiyah (PHIWM), maka perlu adanya kordinasi dan komunikasi yang baik khususnya antar tenaga kependidikan sebagai salah satu elemen warga Muhammadiyah di lingkungan Universitas Muhammadiyah Sukabumi yang memiliki kewajiban untuk mentaati nilainilai yang terkandung dalam PHIWM yang bersumber pada Al-Quran dan Sunnah Rasulullah shallahu alaihi wasalam. Dalam praktiknya, implementasi kebijakan tentang PHIWM pada tenaga kependidikan Univesitas Muhammadiyah Sukabumi dinilai sudah baik. Hal tersebut ditunjukkan dengan adanya komunikasi antar tenaga kependidikan dalam mengusahakan adanya aktivitas-aktivitas yang dapat menunjang peningkatan pemahaman dan pencapaian tujuan-tujuan dari PHIWM serta menunjukkan keteladanan yang baik (uswatun hasanah) menuju terwujudnya masyarakat Islam yang sebenar-benarnya terutama dilingkungan kampus Universitas Muhammadiyah Sukabumi.

\section{Kondisi Lingkungan Ekonomi, Sosial dan Politik}

Kondisi lingkungan ekonomi, sosial dan politik disini merujuk kepada kondisi lingkungan eksternal organisasi. Dalam hal ini, akan menilai sejauhmana kondisi eksternal tersebut berpengaruh dan dapat mendorong keberhasilan implementasi kebijakan publik. Jika kondisi lingkungan tersebut dinilai tidak kondusif, maka akan menimbulkan masalah gagalnya implementasi kebijakan publik.

Jika dilihat, meskipun kebijakan PHIWM ini cenderung diimplementasikan untuk internal suatu kelompok dan tidak terlalu banyak melibatkan pihak-pihak eksternal kecuali masih dalam lingkungan Persyarikatan Muhammadiyah, lingkungan sosial dan politik juga turut berpengaruh pada proses implementasi PHIWM tersebut.

Lingkungan sosial dan politik dalam hal ini Pemerintah Daerah dan masyarakat Kota Sukabumi tetap mendukung adanya aktivitas atau kegiatan Islami sebagai implementasi PHIWM di lingkungan Kampus Universitas Muhammadiyah Sukabumi sebagai salah satu perguruan tinggi di Kota Sukabumi, karena hal tersebut juga sesuai dengan Visi Walikota Sukabumi, yaitu Terwujudnya Kota Sukabumi yang Religius, Nyaman dan Sejahtera. Religius dapat diartikan sebagai perwujudan hidup yang Islami baik dalam lingkungan masyarakat maupun lingkungan lembaga perguruan tinggi yang ada di Kota Sukabumi salah satunya Universitas Muhammadiyah Sukabumi.

Namun demikian dalam praktiknya, implementasi PHIWM di lingkungan Universitas Muhammadiyah Sukabumi saat ini mengalami perubahan yang disebabkan 
oleh kebijakan baik yang dikeluarkan oleh Pemerintah Daerah maupun Pemerintah Pusat tentang adanya PSBB (Pembatasan Sosial Berskala Besar) akibat pandemi Covid-19 yang menyebabkan proses pengelolaan amal usaha dan aktivitas-aktivitas yang berkaitan dengan keagamaan oleh tenaga kependidikan Universitas Muhammadiyah Sukabumi dilakukan secara daring (dalam jaringan/online) atau yang dikenal dengan istilah WFH (Work From Home). Dengan demikian, kondisi lingkungan eksternal (sosial dan politik) tersebut menjadi hal yang berpengaruh dan menjadi penghambat dalam proses implementasi PHIWM pada tenaga kependidikan Universitas Muhammadiyah Sukabumi.

\section{KESIMPULAN DAN REKOMENDASI}

\section{Kesimpulan}

Berdasarkan pembahasan di atas, peneliti dapat menyimpulkan hal-hal sebagai berikut:

1. Dalam dimensi ukuran dan tujuan kebijakan, tujuan PHIWM adalah terbentuknya perilaku individu dan kolektif seluruh anggota Muhammadiyah yang menunjukkan keteladanan yang baik (uswatun hasanah) menuju terwujudnya masyarakat Islam yang sebenar-benarnya. Tujuan ini belum sepenuhnya terealisasikan oleh kalangan tenaga kependidikan Universitas Muhammadiyah Sukabumi. Namun demikian, dalam proses implementasinya terdapat aktivitas-aktivitas yang dapat dijadikan sebagai ukuran yang menunjukkan keteladanan yang baik seperti misalnya pendisiplinan waktu shalat, pengajian rutinan dan aktivitas lainnya yang berkaitan dengan etos kerja dan disiplin amal usaha Muhammadiyah yang mengandung nilai ibadah.

2. Dalam dimensi sumber daya kebijakan, sumber daya yang tersedia dalam proses implementasi kebijakan PHIWM pada tenaga kependidikan Universitas
Muhammadiyah Sukabumi adalah sumber daya manusia, sumber daya sarana dan prasarana, serta sumber daya finansial.

3. Dalam dimensi karakteristik badan pelaksana, salah satu unsur yang berpengaruh terhadap organisasi dalam mengimplementasikan kebijakan adalah tingkat pengawasan hirarki terhadap keputusan-keputusan subunit dan proses-proses dalam badan pelaksana. Dalam proses implementasi PHIWM pada tenaga kependidikan Universitas Muhammadiyah Sukabumi, terdapat adanya dukungan dan sikap yang menunjukkan bahwa pimpinan amal usaha Muhammadiyah harus bisa menciptakan suasana kehidupan Islami dalam amal usaha yang menjadi tanggung jawabnya.

4. Dalam dimensi sikap/kecenderungan pelaksana, terdapat dua dari ketiga unsur pendapat pelaksana yang dapat mempengaruhi kemampuan dan keinginan mereka untuk melaksanakan kebijakan, yaitu arah kecenderungan pelaksana terhadap ukuran dan tujuan kebijakan dan intensitas tanggapan. Terdapat beberapa tanggapan yang memberikan alasan mengapa PHIWM sangat penting untuk diimplementasikan terutama bagi tenaga kependidikan Universitas Muhammadiyah Sukabumi, yaitu: (1) sebagai usaha dalam mewujudkan tujuan Persyarikatan Muhammadiyah, (2) sebagai penuntun dalam mewujudkan kehidupan Islami di lingkungan kampus, (3) sebagai kewajiban warga Muhammadiyah dalam melaksanakan dan mengamalkan ajaran Islam, dan (4) sebagai pedoman tenaga kependidikan dalam memelihara dan mengembangkan amal usaha (UMMI).

5. Dalam dimensi komunikasi antar organisasi dan aktivitas pelaksana, proses implementasi PHIWM pada tenaga kependidikan Universitas Muhammadiyah Sukabumi tidak terlalu banyak 
melibatkan pihak-pihak organisasi eksternal kecuali dalam lingkup Persyarikatan Muhammadiyah. Adapun dalam prosesnya, terdapat komunikasi antar tenaga kependidikan dalam mengusahakan adanya aktivitas-aktivitas yang dapat menunjang peningkatan pemahaman dan pencapaian tujuan dari PHIWM serta menunjukkan keteladanan yang baik (uswatun hasanah) menuju terwujudnya masyarakat Islami yang sebenar-benarnya terutama di lingkungan kampus Universitas Muhammadiyah Sukabumi.

6. Dalam dimensi kondisi lingkungan ekonomi, sosial dan politik, maka kondisi lingkungan ekonomi, sosial dan politik merupakan sejumlah kondisi eksternal yang dapat mendorong sejauhmana keberhasilan implementasi kebijakan. Dalam lingkungan politik, konteks kehidupan Islami telah selaras dengan Visi Walikota Sukabumi. Namun demikian, kebijakan tentang pembatasan sosial berskala besar akibat pandemi Covid-19 yang timbul dari kekuasaan politik baik Pemerintah Daerah maupun Pemerintah Pusat telah berpengaruh pada proses implementasi kebijakan PHIWM di lingkungan Universitas Muhammadiyah Sukabumi. Akibatnya, aktivitas yang menunjang pengelolaan amal usaha dan kegiatan keagamaan tidak dapat dilaksanakan secara langsung.

\section{Rekomendasi}

Rekomendasi dari hasil penelitian ini adalah bahwa dalam rangka mencapai tujuan implementasi PHIWM, pimpinan dan/atau lembaga di lingkungan Universitas Muhammadiyah Sukabumi:

1. Sebaiknya melakukan pengendalian dengan membuat atau menyusun indikator spesifik yang dapat menunjukkan sejauhmana keberhasilan implementasi PHIWM di lingkungan Universitas Muhammadiyah Sukabumi.
2. Sebaiknya meningkatkan pemahaman isi dari PHIWM bagi tenaga kependidikan Universitas Muhammadiyah Sukabumi salah satunya melalui sosialisasi. Hal tersebut bertujuan agar tenaga kependidikan Universitas Muhammadiyah Sukabumi tetap berada dalam koridor dan mengindahkan nilai-nilai yang terdapat dalam PHIWM mulai dari aspek pribadi, organisasi, mengelola amal usaha dan lain-lain.

\section{DAFTAR PUSTAKA}

\section{Buku}

Abdurrahman, Asyumui dkk. (2014). Pedoman Hidup Islami Warga Muhammadiyah (PHIWM). Yogyakarta: Suara Muhammadiyah.

Agustino, Leo. (2006). Politik dan Kebijakan Publik. Bandung: AIPI Bandung dan Puslit KP2W Lemlit Unpad.

Anderson, James E. (1979). Public Policy Making. Second Edition, Chicago, Holt, Rinehart and Winston.

Edward III, George C. (1980). Implementing Public Policy. Washington: Congressional Quarterly, Inc.

Hill, Michael. (1993). The Policy Proses. Harvester-Wheatsheaf; 1st Edition. Edition (1993).

Mazmanian, Daniel A. \& Sabatier, Paul A. (1983). Implementation and Public Policy. Glenview, III: Scott, Foresman and Company.

Nugroho, Riant. (2002). Kebijakan Publik untuk Negara-negara Berkembang. Jakarta: PT Elex Media Komputindo.

Satori, Djam'an \& Komariah, Aan. (2011). Metodologi Penelitian Kualitatif. Bandung: Alfabeta.

Sugiono. (2013). Penelitian Kualitatif, Kuantitatif dan R\&D. Bandung: Alfabeta.

Suharto. (2010). Analisis Kebijakan Publik. Bandung: Alfabeta.

Taufiqurokhman. (2014). Kebijakan Publik. Jakarta: Fakultas Ilmu Sosial dan Ilmu 
Politik Universitas Moestopo Beragama (Pers).

Tachjan. (2008). Implementasi Kebijakan Publik. Bandung: AIPI dan Puslit KP2W Lemlit UNPAD.

Winarno, Budi. (2002). Teori dan Proses Kebijakan Publik. Yogjakarta: Media Pressindo.

\section{Jurnal}

Van Meter, Donald S. \& Van Horn, Carl E. (1975). The Policy Implementation Process, A Conceptual Framework. Administration \& Society, 6(4): 445488. Sage Publications, Inc. https:// doi.org/10.1177/009539977500600 404.

\section{Peraturan}

Anggaran Dasar dan Anggaran Rumah Tangga Persyarikatan Muhammadiyah.

Keputusan Rektor Universitas Muhammadiyah Sukabumi Nomor 1021/KEP/ I.0/A/2020 tentang Revisi Susunan Organisasi dan Tata Kelola (SOTK) Universitas Muhammadiyah Sukabumi.

Surat Izin Operasional Menteri Pendidikan Nasional Nomor 81/D/0/2003 (Surat Izin Operasional UMMI).

Pedoman Hidup Islami Warga Muhammadiyah (PHIWM). 